AperTO - Archivio Istituzionale Open Access dell'Università di Torino

\title{
Graphene oxide-Epoxy hybrid material as innovative photocatalyst
}

\section{This is the author's manuscript}

Original Citation:

Availability:

This version is available http://hdl.handle.net/2318/141423

since 2016-01-07T14:13:47Z

Published version:

DOI:10.1007/s10853-013-7308-7

Terms of use:

Open Access

Anyone can freely access the full text of works made available as "Open Access". Works made available under a Creative Commons license can be used according to the terms and conditions of said license. Use of all other works requires consent of the right holder (author or publisher) if not exempted from copyright protection by the applicable law. 


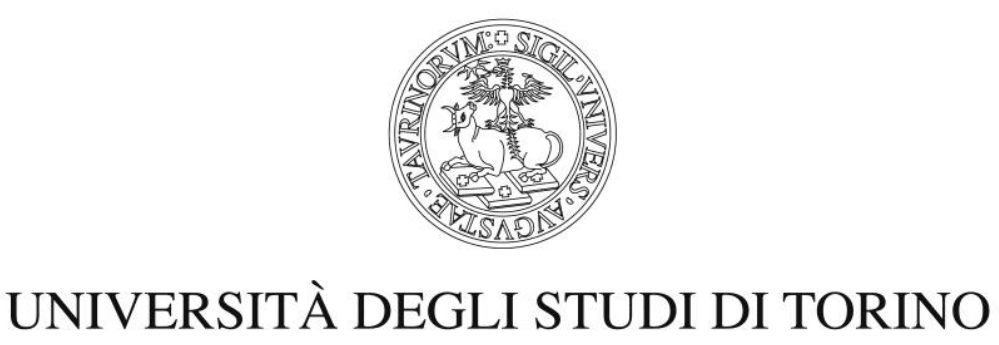

The final publication is available at Springer via http://dx.doi.org/10.1007/s10853-013-7308-7 


\title{
Graphene oxide-epoxy hybrid material as innovative photocatalyst
}

\author{
M. Sangermano ${ }^{1}$, P. Calza ${ }^{2}$ and M. A. Lopez-Manchado ${ }^{3}$
}

(1) Dipartimento di Scienza Applicata e Tecnologia, Politecnico di Torino, C.so Duca degli Abruzzi 24, 10129 Turin, Italy

(2) Dipartimento di Chimica, Università di Torino, V. P. Giuria 5, 10125 Turin, Italy

(3) Instituto de Ciencia y Tecnologia de Polimeros, ICTP-CSIC, Juan de la Cierva 3, 28006 Madrid, Spain

Email: marco.sangermano@polito.it

\begin{abstract}
New photocatalytic materials prepared by dispersing graphene oxide $\left(\mathrm{GO}_{\mathrm{x}}\right)$ into UV-curable epoxy resin can be classified as semiconductors and thanks to this behavior it can be used in order to activate photoxidative process in a similar way as it happens with the well-known $\mathrm{TiO}_{2}$. The activity of these new photocatalytic materials was evaluated in aqueous phase; photoactivity was determined by following the photodegradation of phenol during irradiation in the presence of epoxy crosslinked films containing $\mathrm{GO}_{\mathrm{x}}$.
\end{abstract}

\section{Introduction}

Among the different advanced oxidation processes (AOPs) that have been proposed for the degradation of organic micro-pollutants, $\mathrm{TiO}_{2}$-mediated photocatalysis has shown to be an advantageous technology as it can be carried out under ambient conditions and may lead to complete mineralization of pollutants, yielding carbon dioxide and dilute acids as the final products. $\mathrm{TiO}_{2}$ is by far the most widely used semiconducting material, also because of its chemical inertness, photostability, low cost, and non-toxicity. It is well known that irradiation of $\mathrm{TiO}_{2}$ with an energy source higher than its band gap produces electrons and holes in the conduction band and valence band, respectively. These photogenerated holes and electrons can combine with the surfaceadsorbed species (e.g., water and oxygen) to form highly reactive radical species such as hydroxyl radical and superoxide radical anion and can completely mineralize most organic compounds [1-7]. 
Very recently we find out that carbon nanotubes (CNTs) also can be effective photocatalyst [8]: metallic and semiconducting single-wall carbon nanotubes (SWCNTs) have strong photoabsorption in the UV-spectra. In the diameter range from 0.6 to $1.2 \mathrm{~nm}$, the semiconductors possess optical transition that generally fall within $280-480 \mathrm{~nm}$ wavelength region. Metallic SWCNTs possess optical transition within 390-1800 nm in wavelength, and photoabsorption can produce an electron hole pair or an excitation. This behavior can be used in order to activate photo-oxidative process in a similar way as it happens with $\mathrm{TiO}_{2}$, and in our previous paper the efficiency of CNTs as photocatalyst was assessed.

Similarly graphene oxide $\left(\mathrm{GO}_{\mathrm{x}}\right)$ can be used as photocatalyst and its controlled reduction allowed for progressive tuning of the optical gap from $3.5 \mathrm{eV}$ down to $1 \mathrm{eV}$, while XPS spectra show a concurrent increase in the $\mathrm{C} / \mathrm{O}$ ratio [9].

Reduced $\mathrm{GO}_{\mathrm{x}}$ was already proposed for catalytic oxidation of aqueous organic pollutants [10]. The use of graphene in the preparation of highly photoactive composite materials based on titanium dioxide has already been reported in literature [11]; the synthesized nanocomposites showed enhanced catalytic activity compared to conventional $\mathrm{TiO}_{2}$ photocatalyst.

From a practical point of view the possibility to have the photocatalyst in film form rather than dispersed into aqueous solution will make it more viable due to its easy separation recovery. For this reason in our previous investigations we have dispersed the $\mathrm{TiO}_{2}$ [12] and the SWCNTs [8] into an epoxy matrix and we have investigated their efficiency in photodegradation of a target molecules.

Herein, we report the preparation of UV-cured epoxy films containing $\mathrm{GO}_{\mathrm{x}}$ and its performance in photocatalytic applications. The use of the UV-curing method to prepare the filled polymeric material is particularly attractive since it is an environmentally friendly technique, in which the cured film is prepared starting from the epoxy monomer precursor in the presence of a suitable cationic photoinitiator. The curing process is fast, and occurs at room temperature and in the absence of any solvents. The cationic UV-curing of epoxy in the presence of $\mathrm{GO}_{\mathrm{x}}$ was deeply investigated, the crosslinked films were fully characterized, and the photocatalytic activity was measured by following the degradation of phenol as target molecule; the new proposed catalyst shows a good photocatalytic activity toward the organic pollutant.

\section{Experimental}

\section{Materials}


The 3,4-epoxycyclohexylmethyl 3,4-epoxycyclohexanecarboxylate epoxy resin (CE) was purchased from Aldrich and used as epoxy-based system. Triphenylsulfonium hexafluoroantimonate was used as photoinitiator, and it is commercially available from Aldrich in propylene carbonate solution at $50 \mathrm{wt} \%$.

Functionalized graphene sheets $\left(\mathrm{GO}_{\mathrm{x}}\right)$ were synthesized by the reduction and thermal exfoliation of graphite oxide at $1000{ }^{\circ} \mathrm{C}$ for $30 \mathrm{~s}$. Graphite oxide was previously obtained using natural graphite flakes (purum powder $\leq 0.1 \mathrm{~mm}$, Sigma-Aldrich) following the Brödie method. Graphene produced through this method leads to the formation of single graphene layers or stacks of up to seven sheets with hydroxyl, carbonyl, and epoxy groups on their surface [13]. A full description of the synthesis and characterization of the functionalized graphene sheets (FGS) can be found elsewhere [14].

\section{Sample preparation}

For photocatalytic experiments, the carbon filler was added to the epoxy resin in order to prepare hybrid materials with a content in the range between 1 and 3 parts per hundred resin (phr) with respect to the epoxy resin. The mixtures were stirred with Ultraturrax until a uniform dispersion was achieved. The cationic photoinitiatior was added at $2 \mathrm{wt} \%$ in each formulations, coated on glass substrate and UV irradiated by means of Fusion lamp, with a light intensity on the surface of the sample of about $500 \mathrm{~mW} / \mathrm{cm}^{2}$. UV-cured coatings of about $100 \mu \mathrm{m}$ were achieved.

\section{Polymeric films characterization}

The kinetics of the photopolymerization were determined by Real-Time FT-IR spectroscopy, employing a Thermo-Nicolet 5700 instrument. The formulations were coated onto a silicon wafer. The sample was exposed simultaneously to the UV beam, which induces the polymerization, and to the IR beam, which analyzes in situ the extent of the reaction. Epoxy conversion was followed by monitoring the decrease in the absorbance of the epoxy ring centered at $790 / \mathrm{cm}$. A mediumpressure mercury lamp (Hamamatsu) equipped with an optical guide was used to induce the photopolymerization (light intensity on the surface of the sample of about $30 \mathrm{~mW} / \mathrm{cm}^{2}$ ).

The gel content was determined on the cured films by measuring the weight loss after 24-h extraction with chloroform at room temperature, according to the standard test method ASTM D2765-84. 
Dynamic-mechanical analysis was performed on a Triton instrument at $1 \mathrm{~Hz}$ frequency in tensile configuration, with a stress amplitude of $200 \mu \mathrm{m}$ and a heating rate of $3{ }^{\circ} \mathrm{C} / \mathrm{min}$. The loss factor ( $\tan$ $\delta$ ) and elastic modulus $\left(\mathrm{E}^{\prime}\right)$ were measured from room temperature to $250{ }^{\circ} \mathrm{C}$. The experimental error was below $5 \%$.

The morphological characterizations of the cured films were performed by transmission electron microscopy (TEM Leo 910 microscope at an acceleration voltage of $80 \mathrm{kV}$ ). Ultra-thin sections of the samples were prepared by cryo-ultramicrotomy at $-140{ }^{\circ} \mathrm{C}$ (Leica EM UC6).

\section{Photocatalytic investigation}

Phenol was also used as target molecule to investigate the photocatalytic effect of the UV-cured material. Irradiation experiments were carried out in Pyrex glass cells containing $40 \mathrm{~mL}$ of aqueous solution. The cured epoxy films containing $\mathrm{GO}_{\mathrm{x}}$ were immersed into a $30 \mathrm{mg} / \mathrm{L}$ phenol solution and irradiated. Experiments have been performed in air-saturated conditions using a Blacklit Philips TLK/05 lamp $\left(40 \mathrm{~W} / \mathrm{m}^{2}\right)$ with the maxima emission at $360 \mathrm{~nm}$. The temperature reached during the irradiation was $38 \pm 2{ }^{\circ} \mathrm{C}$. The entire content of the cells was then analyzed with the appropriate techniques. In all cases, experiments were run without modifying the natural $\mathrm{pH}$ of the solution.The disappearance of phenol as a function of the irradiation time was followed using an HPLC system (Merck-Hitachi L-6200 pumps), equipped with a Rheodyne injector, a RP C18 column (Lichrochart, Merck, $12.5 \mathrm{~cm} \times 0.4 \mathrm{~cm}, 5 \mu \mathrm{m}$ packing), and a UV-Vis detector (Merck-Hitachi L-

4200) set at $220 \mathrm{~nm}$, using as eluent acetonitrile and phosphate buffer $\left(1 \times 10^{-2} \mathrm{M}\right)$ at $\mathrm{pH} 2.8$ at a flow rate of $1 \mathrm{~mL} / \mathrm{min}$.

\section{Results and discussion}

\section{Photo-curing process and film characterization}

The effect of the graphene on the UV-curing process was evaluated by RT-FTIR analysis. In Fig. 1 we report the conversion curves as a function of irradiation time for the pristine epoxy resin and for the epoxy formulation containing $\mathrm{GO}_{\mathrm{x}}$ in the range between 1 and $3 \mathrm{phr}$; the conversion curves of all samples were calculated from the normalized absorbance of the epoxy (centered around 750/cm) by the carbonyl band (centered at $1700 / \mathrm{cm}$ ). 


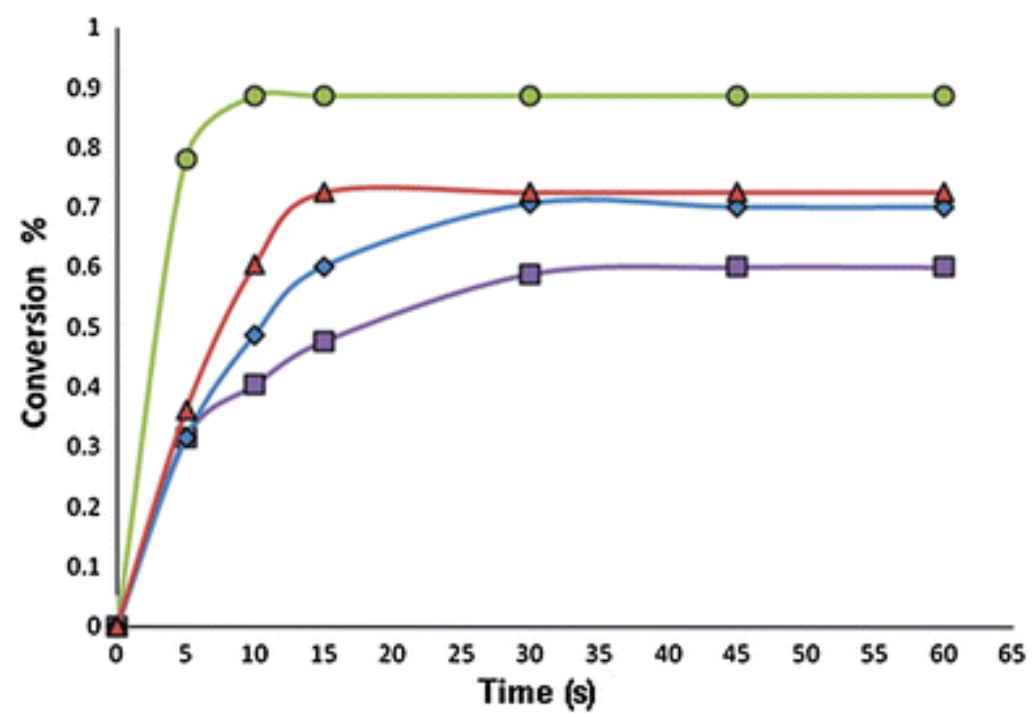

Fig. 1 Conversion curves as a function of irradiation time for the pristine epoxy resin (filled circle) and for the epoxy formulation containing, respectively, $1 \mathrm{phr}$ (filled triangle), $2 \mathrm{phr}$ (filled diamond), and $3 \mathrm{phr}$ (filled square) of $\mathrm{GO}_{\mathrm{x}}$. Film thickness $25 \mu \mathrm{m}$, light intensity $30 \mathrm{~mW} / \mathrm{cm}^{2}$

While the slope of the curves gives an information of the kinetic of the process, the plateau value gives the final epoxy group conversion.

From the curves reported in Fig. 1, the high reactivity of the epoxy groups of the CE resin with a quite high initial rate of polymerization is evident. The epoxy group conversion levels off, after 1 min of irradiation, to a value of about $88 \%$. This is due to the formation of a glassy polymer network, which hindered the mobility of the reactive species so that a large number of unreacted epoxy groups remained trapped within the glassy polymer network.

The addition of graphene to the photocurable formulations led to a decrease of both the polymerization rate and the final conversion as a function of loading fraction. The epoxy group conversion decreased to a minimum of $60 \%$ at 3 phr GO x content. The relatively lower rate of conversion may be due to the UV-light shielding effect of graphene: a lower amount of reactive species is photogenerated resulting in a decrease of the epoxy group conversion. These data are in accordance with previous investigations $[15,16]$.

All the cured samples showed a high gel content value (above $99 \%$ ), demonstrating the absence of any extractable oligomer or unreacted monomer. This is an indication of the efficiency on crosslinking reaction even in the presence of the carbon filler.

Dynamic-mechanical analysis was performed on the UV-cured films, which allows the evaluation for the elastic and viscous components of the modulus of the material over a large temperature range. It was possible to observe a strong increase of the $\mathrm{T} g$ value as a function of the graphene content in the UV-curable formulations (see Table 1). The pristine epoxy matrix shows a main 
relaxation process $\alpha$ at around $193{ }^{\circ} \mathrm{C}$, assigned to the glass transition temperature (see Fig. 2). This relaxation is gradually shifted toward higher temperatures with increasing graphene content in the composite.

Table 1 Properties of UV-cured epoxy films obtained

\begin{tabular}{|l|l|l|l|}
\hline Sample & Final Conv. $(\boldsymbol{\%})^{\mathbf{a}}$ & Gel content $(\boldsymbol{\%})^{\mathbf{b}}$ & $\mathbf{T}_{\mathbf{g}}\left({ }^{\circ} \mathbf{C}\right)^{\mathbf{c}}$ \\
\hline $\mathrm{CE}$ & 88 & 100 & 193 \\
\hline $1 \mathrm{phr} \mathrm{GO}_{\mathrm{x}}$ & 72 & 100 & 2205 \\
\hline $2 \mathrm{phr} \mathrm{GO}_{\mathrm{x}}$ & 70 & 100 & 222 \\
\hline $3 \mathrm{phr} \mathrm{GO}_{\mathrm{x}}$ & 60 & 99 & 243 \\
\hline
\end{tabular}

${ }^{a}$ Plateau values of the RT-FTIR conversion curves as a function of irradiation time

${ }^{\mathrm{b}}$ Determined gravimetrically ASTM D2765-84

${ }^{\mathrm{c}}$ Determined by DMTA analysis, tensile configuration, $1 \mathrm{~Hz}$ frequency

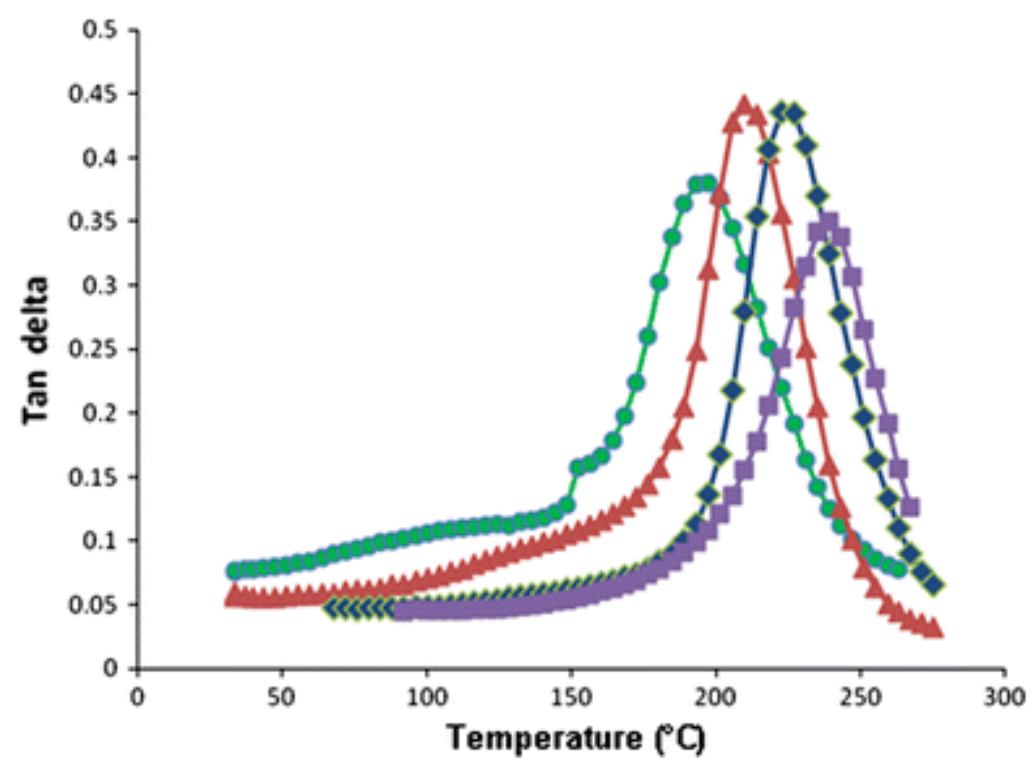

Fig. 2 Tan $\delta$ values obtained by DMTA analyses of the UV-cured pristine epoxy resin (filled circle) and for the epoxy formulation containing, respectively, $1 \mathrm{phr}$ (filled triangle), $2 \mathrm{phr}$ (filled diamond), and $3 \mathrm{phr}$ (filled square) $\mathrm{GO}_{\mathrm{x}}$. Film thickness $100 \mu \mathrm{m}$

The $\mathrm{T}_{\mathrm{g}}$ increase could be due to the constraint effect of graphene sheets on the polymer chain mobility. These results suggest a uniform and homogeneous distribution of the graphene platelets within the polymeric network.

Morphological investigations of the crosslinked materials were performed by microscopic analyses. TEM image for the CE/graphene composites containing 2 phr of $\mathrm{GO}_{\mathrm{x}}$ (Fig. 3) shows that single 
graphenes or stacks of graphene with thicknesses of several nanometers were uniformly dispersed throughout the polymer matrix. The particles appear to be completely embedded in the epoxy resin indicating an intercalated structure.

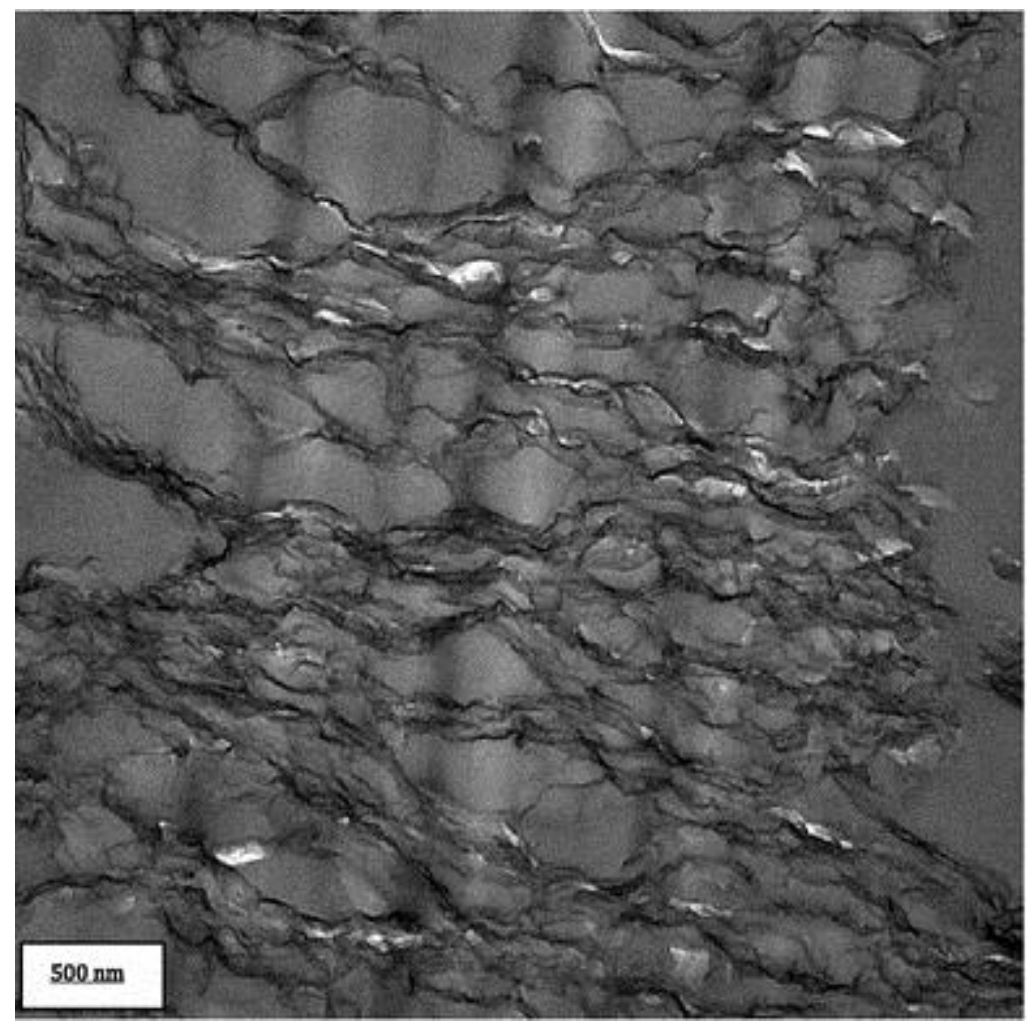

Fig. 3 TEM images of graphene-epoxy composite at a 2-phr content of $\mathrm{GO}_{\mathrm{x}}$

\section{Photodegradation activity}

The photoactivity of the prepared materials in aqueous solution was studied using phenol as target molecule. As previously reported [12] direct photolysis scarcely contributes to the phenol transformation; upon light exposure in pure water or with pristine film their degradation is negligible even after long irradiation times (14 days). A blank experiment was performed with the epoxy film containing $3 \mathrm{phr}$ of $\mathrm{GO}_{\mathrm{x}}$, immersed in the phenol aqueous solution and kept in the dark; a decrease of phenol concentration of about $20 \%$ was measured after $72 \mathrm{~h}$, attributable to an adsorption process which could probably be enhanced by the $\mathrm{GO}$ x dispersed into the polymeric film, since it is characterized by a very high surface area.

The efficiency of the prepared films containing increasing amounts of $\mathrm{GO}_{\mathrm{x}}$ was then evaluated upon light exposure; the disappearance curves as a function of irradiation time are plotted in Fig. 4. Photodegradation efficiency enhances by increasing the $\mathrm{GO}_{\mathrm{x}}$ content: while immersing the film containing $1 \mathrm{phr}$ of $\mathrm{GO}_{\mathrm{x}}$ in the solution we could observe that phenol is only scarcely degraded ( $30 \%$ after $72 \mathrm{~h}$ of irradiation); by using the film containing $1.5 \mathrm{phr}$ of $\mathrm{GO}_{\mathrm{x}}$, the $\mathrm{t}_{1 / 2}$ becomes $37 \mathrm{~h}$. 
This value further reduced to $10 \mathrm{~h}$ when it was immersed in the film containing $2 \mathrm{phr}$ of $\mathrm{GO}_{\mathrm{x}}$; in this case, the target molecule is completely degraded within $72 \mathrm{~h}$ of irradiation. At higher concentrations of filler in the polymeric films ( 2.5 and $3 \mathrm{phr}$ of $\left.\mathrm{GO}_{\mathrm{x}}\right)$, the photodegradation efficiency levels off, and no further improvement was obtained by increasing the $\mathrm{GO}_{\mathrm{x}}$ content up to $3 \mathrm{phr}$, similar to what was already documented with high $\mathrm{TiO}_{2}$ content [17]. This phenomenon is attributable to the photonic efficiency level off at high catalyst concentration, when the increased light scattering reduces the photonic flux within the irradiated solution thus lowering the degradation rate [2].

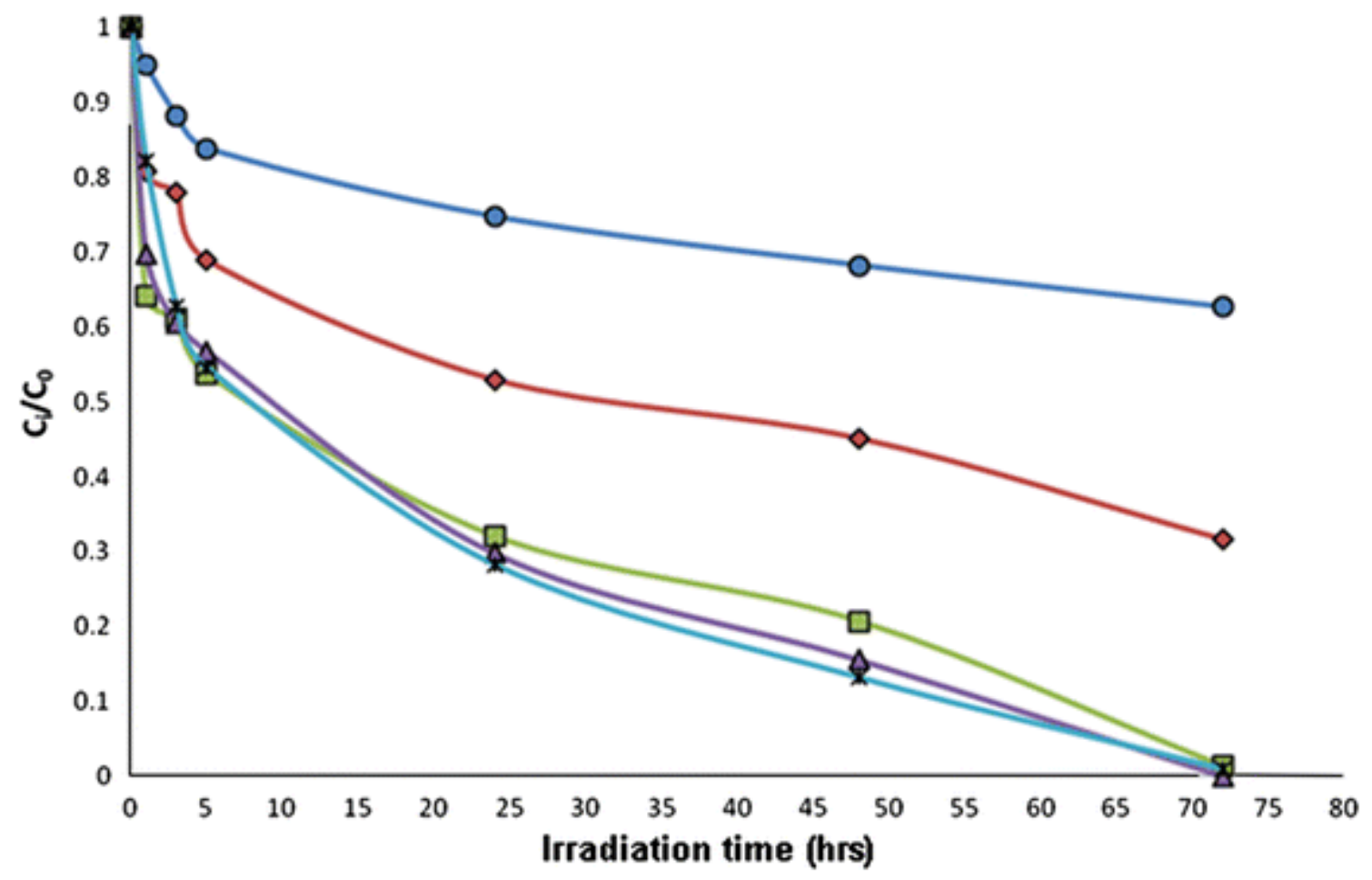

Fig. 4 Phenol degradation rate as a function of irradiation time using epoxy film containing $1 \mathrm{phr}$ (filled circle), 1,5 phr (filled diamond), $2 \mathrm{phr}$ (filled square), 2,5 phr (filled triangle), and $3 \mathrm{phr}$ (asterisk) $\mathrm{GO}_{\mathrm{x}}$

All these data strongly support the evidence of a photocatalytic activity of the $\mathrm{GO}_{\mathrm{x}}$ dispersed within the epoxy network together with a certain degree of adsorption, which in any case will help the removal of the pollutants from water.

\section{Conclusions}

In this paper we have investigated the efficiency of epoxy-GO $\mathrm{x}_{\mathrm{x}}$ hybrid material as photocatalyst on aqueous phase. It was calculated that $\mathrm{GO}_{\mathrm{x}}$ presents progressive tuning of the optical gap from 
$3.5 \mathrm{eV}$ down to $1 \mathrm{eV}$. Therefore, it can be classified as semiconductors and thanks to this behavior it can be used in order to activate photo-oxidative process in a similar way as it happens with the wellknown $\mathrm{TiO}_{2}$.

Epoxy films containing $\mathrm{GO}_{\mathrm{x}}$ in the range between 1 to $3 \mathrm{phr}$ were prepared by means of UV induced polymerization.

The activity of these new photocatalytic materials was evaluated in aqueous phase; photoactivity was determined by following the photodegradation of phenol during irradiation in the presence of the UV-cured epoxy films containing $\mathrm{GO}_{\mathrm{x}}$. The target molecule is degraded completely in about $72 \mathrm{~h}$ of irradiation when the crosslinked films contains $3 \mathrm{phr}$ of $\mathrm{GO}_{\mathrm{x}}$. The disappearance of the target molecule could occur through two concomitant effects: the photodegradation and the adsorption process: both phenomena will be useful for eliminating the pollutants from water.

While $\mathrm{GO}_{x}$ powder was already studied as efficient photocatalyst, especially coupled with $\mathrm{TiO}_{2}$, this is the first scientific investigation in which the potential application in pollution degradation was studied by adding the $\mathrm{GO}_{\mathrm{x}}$ into a polymeric film, and this is quite interesting since $\mathrm{GO}_{\mathrm{x}}$ will make it more viable due to its easy separation recovery.

\section{Acknowledgements}

This research is supported by a Marie Curie International Research Staff Exchange Scheme Fellowship (PHOTOMAT, proposal n. 318899) within the 7th European Community Framework Programme.

\section{References}

1. Fujishima A, Hashimoto $\mathrm{K}$, Watanabe $\mathrm{T}$ (1999) $\mathrm{TiO}_{2}$ photocatalysis, fundamentals and applications. Bkc Inc, Tokyo, p 128

2. Konstantinou IK, Albanis TA (2003) Appl Catal B Environ 42:319

3. Hoffman MR, Martin ST, Choi W, Bahnemann DW (1995) Chem Rev 95:69

4. Thompson TL, Yates JT (2006) J Chem Rev 106:4428

5. Calza P, Sakkas VA, Medana C, Azharul Islam A, Raso E, Panagiotou K, Albanis T (2010) Appl Catal B Environ 99:314

6. Minero G, Mariella V, Maurino E, Pelizzetti E (2000) Langmuir 16:2632

7. Serpone N, Pelizzetti E (1989) Photocatalysis fundamentals and applications. Wiley Interscience, Amsterdam

8. Sangermano M, Pinneri S, Calza P, Paganini C (2012) Macromol Mater Eng 297:353 
9. Mathkar A, Tozier D, Cox P, Ong P, Galande C, Balakrishnan K, Leela A, Ajayan PM (2012) J Phys Chem Lett 3:986

10. Selim Arif Sher Shah M, Reunm Park A, Zhang K, Hyeok Park J, Yoo PJ (2012) Appl Mater Interface 4:3893

11. Stengl V, Popelkova D, Vlacil P (2011) J Phys Chem C 115:25209

12. Calza P, Rigo L, Sangermano M (2011) Appl Cat B 106:657

13. Schniepp HC, Li JL, McAllister MJ, Sai H, Herrera Alonso M (2006) J Phys Chem 110:8535

14.Verdejo R, Barroso Bujans F, Rodriguez Perez M, de Saja J, Lopez Manchado M (2008) J Mater Chem 18:2221

15.Sangermano M, Pegel S, Potschke P, Voit B (2008) Macromol Rapid Commun 29:396

16.Marting-Gallego M, Verdejo R, Lopez-Manchado MA, Sangermano M (2011) Polymer 52:4664

17. Nohara K, Hidaka H, Pelizzetti E, Serpone N (1997) J Photochem Photobiol A Chem 102:265 